University of Warwick institutional repository

This paper is made available online in accordance with

publisher policies. Please scroll down to view the document

itself. Please refer to the repository record for this item and our

policy information available from the repository home page for further information.

To see the final version of this paper please visit the publisher's website. Access to the published version may require a subscription.

Author(s: Richard Lampard

Article Title: Is Social Mobility an Echo of Educational Mobility? Parents'

Educations and Occupations and Their Children's Occupational

Attainment

Year of publication: 2007

Link to published version: http://www.socresonline.org.uk/12/5/16.html

Publisher statement: None 
Is Social Mobility an Echo of Educational Mobility?

Parents' Educations and Occupations and their Children's

Occupational Attainment.

[Pre copy-editing version: August 2007]

Richard Lampard

\section{Biographical note}

Richard Lampard is a Senior Lecturer in the Department of Sociology at the University of Warwick. His current research interests include social and educational mobility, the impact of family structure on educational outcomes, the formerly partnered and repartnering, and various other aspects of union formation and dissolution.

Department of Sociology

University of Warwick

Gibbet Hill Road

Coventry CV4 7AL

United Kingdom

Email: Richard.Lampard@warwick.ac.uk 


\title{
Is Social Mobility an Echo of Educational Mobility? \\ Parents' Educations and Occupations and their Children's \\ Occupational Attainment.
}

\begin{abstract}
Quantitative studies of occupational attainment and intergenerational social mobility have often devoted little attention to the roles of parental education and educational inheritance. Informed by the ideas of authors who see class reproduction as reflecting more than occupations and economic resources (including Devine, Savage and Crompton), this paper assesses the importance of parents' educations, and considers the relevance of education to class analysis and class reproduction processes.
\end{abstract}

Logistic regressions using British Household Panel Survey (BHPS) data establish the relative importance of parents' educations and parents' occupational classes as determinants of children's attainment of service class occupations. These multivariate analyses reiterate the salience of mother's class, but also show that mother's education has an independent impact. However, this is more limited if both parents can be assigned to classes. The only difference between daughters and sons that is found in the impact of parental characteristics is a weaker impact of father's class on daughter's occupational attainment than on son's occupational attainment. For both daughters and sons, mother's education and mother's class have an impact. 
The relationship between parents' and children’s educations accounts for relatively little of the relationship between parents' and children's occupational classes. Hence intergenerational class mobility patterns do not simply echo intergenerational educational mobility patterns. However, an examination of the direct and indirect effects of parents' educations and classes on children's occupational attainment shows parental education to play a substantial role in the intergenerational transmission of advantage, and indicates that part (but not all) of the relationship between class origin and occupational attainment can be explained in terms of the intergenerational transmission of cultural capital. In contrast, a substantial part of the indirect effect of parental class via children's qualifications does not reflect parental education. Hence the conversion of parental economic resources into children's educational credentials also appears important.

\section{Keywords}

Educational mobility; class mobility; social mobility; occupational attainment; class inequality; service class; mother’s education; mother’s class; cultural capital; credentialism. 


\section{Is Social Mobility an Echo of Educational Mobility? \\ Parents' Educations and Occupations and their Children's \\ Occupational Attainment.}

\section{Introduction}

In many earlier studies of social mobility or occupational attainment the role of parents' educational characteristics has not been a central concern. Often, such studies have not included parents' educations within their analyses. Sometimes no data relating to parents' educations have been available, but in many instances parents' educations do not appear to have been perceived as being of conceptual importance. Hence in this paper, statistical analyses are used to examine the impact of parents' educational attainments, in order to assess the empirical importance of parents' educations and also to highlight their conceptual significance.

One of the empirical objectives of this paper is to establish the degree of dependence of one form of intergenerational mobility, occupational class mobility, on another, educational mobility. ${ }^{1}$ Given that past studies of social mobility and occupational attainment have shown children's educational attainment to be an important mediator of the relationship between parents' and children's occupational classes (Breen and Jonsson 2005: 233), much of this relationship between classes could be a by-product of the relationship between parents' and children's educational attainments. In other words, the extent of social mobility within a society might largely be an 'echo' of the extent of educational mobility. 
A broader empirical objective of this paper is to establish how important parents' educational achievements are, as direct or indirect determinants of children’s occupational attainment. In an earlier paper focusing on Britain (Lampard 1995), both parents’ occupational classes were shown to have an impact on children's occupational attainment, or, more precisely, attainment of an occupation within the service class. This paper builds upon that earlier consideration of the impact of parental characteristics, utilising data relating to parents' educational achievements that have since become available.

The earlier paper suggested that incorporating mother's education within an analysis of children’s occupational attainment would be desirable (Lampard 1995: 718, 725), since the available information regarding mother's occupation may not constitute an adequately full or reliable measure of the mother's social position from a stratification perspective. $^{2}$ There is a limited amount of evidence, mostly from North American or continental European studies, that parental education has an impact within analyses that control for parents' occupations. Thus, just as mother's occupational class has too marked an impact to be ignored when establishing a family’s class position within analyses of children's occupational attainment (Lampard 1995: 726), parents' educational achievements may also make a sufficiently important contribution to the explanation of children's occupational attainment to demand attention.

Both the above empirical objectives relate to the broader issue of the role of education in intergenerational 'class reproduction', or, to put it in more general terms, the intergenerational "reproduction of advantage” (Devine 1998: 31). Two linked themes 
visible within recent discussions of class analysis in general and class reproduction in particular are of relevance in this context. First, authors such as Crompton and Scott (2000: 1-3) suggest that it is not self-evident that 'classes' in contemporary society (in the sense of hierarchical social groupings that show a tendency towards intergenerational reproduction) should be conceptualised solely in terms of occupational categories. More specifically, Gershuny (2000: 43) has developed an "indicator of social position", to be used as an alternative to class in the analysis of life-chances (Crompton and Scott 2000: 9), which incorporates education (in the form of highest educational qualification). In general, the reproduction of advantage may involve social positions that can be defined appropriately in educational as well as occupational terms. ${ }^{3}$ Thus analyses of educational mobility may be of equal relevance to analyses of occupational class mobility.

Second, an important criticism that is made of authors such as Goldthorpe (1996, 2000), who define class in terms of employment relations and 'employment aggregates’ (Crompton 1998), is that their approach fails to encompass the cultural dimension of 'class', or of the reproduction of advantage more generally (Crompton 2006: 660; Devine 1998: 23). This criticism is frequently accompanied by discussion of the ideas of Bourdieu (1973, 1984), who “does not ultimately reduce class to economic relations or position in the division of labour” (Savage et al. 2005: 41). Bourdieu’s ideas about cultural capital and its intergenerational transmission constitute a useful counter-balance to Goldthorpe's emphasis on the role of economic resources in class reproduction, although the ideas of both authors are open to criticism (Devine 1998: 28-32). ${ }^{4}$ 
Whether one views class reproduction as being determined by parents' economic resources, or as reflecting their cultural capital, or as linked to both of these, children's education has been shown to be (and is widely accepted as being) a key aspect of the mechanism via which the intergenerational transmission of advantageous class positions operates (e.g. Marshall et al. 1997; Devine 2004). As discussed in the next section, parents' educations have not received the same degree of attention in studies of occupational attainment. However, they have frequently been linked conceptually to the idea of cultural capital, and have been shown to have an impact on children's educational attainment. As such, parental education can be viewed as an important component of the cultural element of the process of class reproduction.

While Crompton views the material and cultural "strands of the transmission of class advantage and disadvantage via the family” as interwoven (Crompton 2006: 661), she also states that "[t]he processes of material and cultural reproduction are inter-twined, but analytically, they may be treated as distinct.” (Crompton 2006: 673). Conversely, other authors suggest that the economic and cultural determinants of 'class position' (and the economic and cultural dimensions of processes of 'class reproduction') need to be considered simultaneously and in an analytically integrated fashion (Devine and Savage 2000: 193; Devine 2004: 182; Savage et al. 2005: 41). One implication of adopting this latter position would seem to be that parents' educations have a potentially important role to play in analyses of class reproduction in general.

Of course, parents' educations may also be an important aspect of the economic dimension of the intergenerational transmission of class position. Furthermore, given that the conversion of economic resources into cultural resources (and vice versa) has 
been argued to be a key aspect of the process of class reproduction (Devine 2004: 178; Savage et al. 2005: 44), making a distinction between 'economic' and 'cultural' aspects of class reproduction when reflecting upon the relevance of parents’ educations is over-simplistic. What is crucial to an assessment of the relevance of parents' educations is whether they constitute an important aspect of the overall social positions of children's families of origin. Of equal importance are the roles that parental education may play in the processes via which advantage is transmitted intergenerationally.

\section{Literature review}

This review concentrates upon some relevant aspects of the approaches and findings of past empirical studies. It starts with an assessment of past (quantitative) studies examining the impact of parental characteristics on children's occupational or educational attainment. This assessment highlights the characteristics that are included and excluded and their relative explanatory importance. Before focusing on studies corresponding to Britain and other European countries, the review considers relevant aspects of North American studies, including studies belonging to the status attainment tradition exemplified by Blau and Duncan (1967). However, the relevance of findings relating to parental education from other countries is constrained by variations between national educational systems.

The review moves on to an examination of the ways in which parental education has been seen to fit conceptually into the intergenerational transmission of cultural and socio-economic status. It refers to studies that explicitly or implicitly highlight the 
possibility that the relationship between parents' and children's educations underpins intergenerational class mobility, although the concerns and approaches of past authors have not led them to explore this possibility.

\section{Parental characteristics in North American studies}

Frequently, studies of occupational attainment in North America have failed to consider the impact of mother's occupation (Warren et al. 2002), sometimes because of a lack of data (Treiman and Terrell 1975), perhaps reflecting the historical 'rarity' of employed mothers (Pearson 1983: 214). Where studies of women's occupational attainment have incorporated mother's occupation, they have typically found it to be of broadly equivalent importance to father's occupation, but such studies have often not considered parents’ educations (Rosenfeld 1978; Pearson 1983; Stevens 1986). Not all studies that have examined the effect of parental education have found it to be of significance (McClendon 1976), but Hayes and Miller (1993: 662-3) discuss a small number of studies that have examined the effects of both parents' occupations and educations simultaneously, and have identified educational effects. Some studies that have examined the effects of both parents' characteristics have reported effects to be stronger where a parent and child are of the same sex (Stevens 1986: 160; Miller and Hayes 1990: 63). Overall, despite the lack of emphasis on mother's occupation and parents' educations, research focusing on North America has shown that these can be of explanatory importance. 
Parents' educations in British or European studies

Relatively few British or European studies have examined the impact of both parents' educations on children's occupational attainment. Studies that have (Egerton 1997; Bond and Saunders 1999), like studies considering father's education only (Western 1999), have sometimes operationalised parental education quite crudely, using small numbers of school-leaving age categories. ${ }^{5}$ Even studies of educational outcomes have often focused on one parent’s education only (Jæger and Holm 2003; Comi 2003; see also Breen and Jonsson 2005: 225), or have combined father's and mother's educations within a single measure (Erikson and Jonsson 1998; De Graaf et al. 2000; Sieben and De Graaf 2001; Sullivan 2001), despite both parents’ educations being important determinants of children's educational attainment (Halsey et al. 1980: 87; Dearden et al. 1997: 57; Korupp et al. 2002: 37; Chevalier et al. 2003: 3; Sieben and De Graaf, 2003: 47).

In educational attainment studies, parents' educations are seldom treated as of primary explanatory importance, often being viewed as one aspect of the broader concept of ‘family background' (Jonsson and Erikson 2000: 356; Sieben and De Graaf 2001: 441; Chevalier and Lanot, 2002: 179), or even simply as something to be controlled for in analyses of the impact of class origin (Goldthorpe 1996: 497). Indeed, inequalities in educational attainment are frequently assessed primarily with reference to class origin (Halsey et al. 1980: 201; Jonsson and Erikson 2000: 369; Breen and Jonsson 2005: 225). In relatively recent studies of educational or occupational attainment, class origin has often still been operationalised using father's occupation only (Egerton 1997; De Graaf and Kalmijn 2001; Sieben and De Graaf, 2003; see also 
Breen and Jonsson 2005), or the 'dominant' parental occupation (Erikson and Jonsson 1998; Sullivan 2001), despite evidence that father's and mother’s occupations have independent effects on children’s attainment (Lampard 1995: 725; Hayes and Miller 1989: 443).

Parents' educations have been shown to have a non-negligible effect upon children's educational attainment, controlling for the impact of parental class (Egerton 1997: 275; Sieben and De Graaf 2001: 451), but the extent to which parents' educations have been found to have direct effects on children's occupational attainment has depended upon the other variables included within multivariate analyses. Kerckhoff et al. (1982: 353), Hayes and Miller (1989: 443), and Bond and Saunders (1999: 236) found no direct effects, and Western (1999: 442) found a very limited direct effect of father's education on son's occupational class attainment, but Erikson and Jonsson (1998: 24-5) found effects of parents' educations within parents’ classes, and Egerton (1997: 277) found persisting effects of both parents’ educations, controlling for children's qualifications and ability, although this may reflect the measures that she used. $^{6}$

Viewed collectively, past quantitative studies of occupational and educational attainment have not ascribed the same conceptual significance to parents' educations as they have to parents' occupational classes, especially father's class. The patchy evidence for direct effects of parental education on occupational attainment, and the limited magnitude of the effects that have been identified, may have contributed to this tendency. However, as will be suggested later in this paper, the indirect effects of parental education constitute a key aspect of its overall relevance. By neglecting the 
importance of these effects, past studies have perpetuated the under-estimation of the significance of parental education in the context of processes of class reproduction.

Parental education and the intergenerational transmission of cultural and socioeconomic status

Lareau and Weininger (2003) have pointed out that empirical studies utilising the concept of 'cultural capital' in ways that apparently reflect the ideas of Bourdieu (1984 [1979]) have often interpreted the concept in a narrower way than Bourdieu may have intended. More specifically, such studies have often focused on indicators relating to participation in ‘highbrow’ cultural activities (Lareau and Weininger 2003: 575), whereas Bourdieu's understanding of the term appears broader, and he does not view cultural capital as distinct from, or independent of, technical skills and 'ability' (2003: 580). Despite their assertion that a ‘dominant interpretation’ of cultural capital has emerged (2003: 569), Lareau and Weininger acknowledge the existence of variations in approach to the concept of cultural capital among studies broadly adopting the dominant interpretation (2003: 576).

It is thus unsurprising that studies vary in their operationalization of cultural capital (Sullivan 2001: 896; De Graaf et al. 2000: 107-8), and also in how they see it as relating to parental education. Parental education is sometimes viewed as an acceptable proxy for parental cultural capital (Halsey et al. 1980: 198; Egerton 1997), although other authors interpret it as constituting 'human capital' (Chevalier et al. 2003: 2). However, authors using it as a proxy for cultural capital sometimes acknowledge its potential inadequacy in this context (Jæger and Holm 2003: 16), and 
those generating dedicated measures of cultural capital view this practice as problematic (De Graaf et al. 2000; Sullivan 2001: 896). Nevertheless, while parental education may not be an appropriate proxy for cultural capital, cultural capital and human capital are arguably both transmitted and also created by education (Halsey et al. 1980: 199; Goldthorpe 1996: 488; Gunn, 2005: 58; Becker and Tomes 1986: S6).

Authors differ as to whether they see parental education as more strongly linked to parental cultural status or to parental socio-economic status. Some contrast the effects of parental education and parental income (Comi 2003: 17), but others view parental education as indicating parents’ socio-economic position (De Graaf et al. 2000: 107; Sieben and De Graaf, 2003: 39). Similarly, some authors see parental occupational class as indicating socio-economic position, once parental education and/or cultural capital have been taken into account (Sullivan 2001: 893; Jæger and Holm 2003: 16), but others see parental class as relating both to cultural capital and also to other assets or resources (Egerton 1997: 277).

Arguably, it is not constructive to attempt to match parental education and parental class to cultural capital and socio-economic resources in a one-to-one fashion. De Graaf and Kalmijn (2001) exhibit a flexible way of thinking about the relationships between class, education, and the transmission of cultural and economic status, suggesting that parental class incorporates cultural and economic dimensions that can be transmitted directly, or indirectly via children’s education. Savage et al. (2005) propose a flexible approach to thinking about the intergenerational transmission of cultural and economic status that is similarly of value. This approach draws upon the ideas of Bourdieu (1997) regarding different types of capital (economic, cultural, 
social, symbolic) and the scope for converting, say, cultural capital into a more 'fieldspecific’ form such as educational capital. ${ }^{7}$ Such flexible approaches can accommodate the perspectives of authors who see differential educational outcomes as reflecting rational action given class-based differentials in the distribution and investment of (economic) resources (Goldthorpe 1996: 497; Ultee and Luijkx 2003: 7), as well as the perspectives of authors who concentrate upon the impact of classrelated differentials in cultural capital on educational attainment (Sullivan 2001: 894).

An appropriately cautious approach would seem to be to view both parental class and parental education as indicators of parents' cultural characteristics and also of their socio-economic characteristics, but to assume that parental class is more closely related to economic resources and that parental education is more closely related to cultural capital.

Social mobility as an echo of educational mobility?

A recurring idea within the literature (albeit sometimes implicit) is that another relationship may underpin intergenerational class or earnings mobility. The range of possible underlying relationships that have been suggested in this context includes: the relationship between parents' and children's educations (Dearden et al. 1997: 57), the relationship between the educational or status levels of parents' and children's occupations (Western 1999: 445), a 'circuit of cultural capital' (Savage et al. 2005: 44), and the intergenerational transmission of human capital (Becker and Tomes 1986: S31). Similarly, Jonsson and Erikson (2000: 377) imply that class differentials in educational attainment may reflect the intergenerational preservation of educational 
advantages. However, while the persistence of direct class effects on occupational attainment, controlling for indirect effects via education, is often examined (Egerton 1997: 277; Erikson and Jonsson 1998: 19; Bond and Saunders 1999: 245; Breen and Jonsson 2005: 233), the extent to which the relationship between parents' and children's classes reflects some other intergenerational relationship has not been examined explicitly.

Focusing on the possibility that social mobility simply echoes the relationship between parents and children's educational qualifications necessitates a concern with the role of formal educational credentials in occupational attainment, akin to that which gained visibility in the work of 'LSE school' authors such as Glass, Halsey and Westergaard (Payne 1987: 124-5). However, these authors, like the subsequent literature on educational attainment more generally, also have a concern with trends in class-related inequalities which is of less relevance in this context. Class differences in educational attainment are not of direct relevance, since what is needed for this form of educational mobility to account for social mobility is simply a high level of credentialism within each generation, plus a strong degree of educational inheritance.

In some studies, much of the impact of educational inheritance on occupational attainment has been obscured by an emphasis on direct effects. The direct effect of parental education in an analysis including a child's own education corresponds to the part of the overall effect that does not operate via educational inheritance. Even if the child's own education is not included, any indirect effects of parental education via parental class may still be obscured. Unfortunately, the level of attention paid to indirect effects rarely matches that exhibited by Hayes and Miller (1989: 443). 
The relatively few studies focusing explicitly upon educational mobility often view it as measuring equality of opportunity within a society, or societal openness, as facilitated by the educational system and state (Chevalier et al. 2003: 11; Comi 2003: 2; Ultee and Luijkx 2003: 3-6). ${ }^{8}$ The absence of a sociological study examining the role played by educational mobility, or more precisely patterns of educational inheritance, in underpinning patterns of intergenerational social class mobility may at first sight seem surprising. Typically, however, in studies which focus upon the relationship between class and education, sociologists appear either to conceptualise education simply as a vehicle via which particular occupational class positions may be reached, or to view educational attainment simply as one of a range of outcomes that depend upon class background. Hence the possibility that the intergenerational transmission of socio-economic position is driven by the ability of children to capitalise in some way upon their parents' 'educational capital' has not been explored. In consequence, the possibility that education is a concept that is as important as (or more important than) occupational class, in the context of the intergenerational reproduction of the social stratification of contemporary societies, has also been neglected.

In conclusion, the preceding review of past quantitative studies suggests that a study of the intergenerational transmission of occupational advantage should place a greater emphasis on parental education and its effects (whether indirect or direct) than has typically been the case in earlier studies, but also suggests that caution needs to be exercised in relation to assuming too close a match between parental education or parental class and cultural capital or economic resources. 


\section{Data and methods}

This paper uses data for 1991-2004 from Waves 1-13 of the British Household Panel Survey (BHPS), including the work-life history files discussed by Halpin (1997), specifically those incorporating Wave $12 .^{9}$

\section{Dependent and independent variables}

The dichotomous dependent variable indicates whether individuals who had ever had an occupation had at some stage had one in the 'service class', as defined by the Goldthorpe class schema (Goldthorpe et al. 1987: 40-43). ${ }^{10}$ The data used to derive the dependent variable came primarily from the work-life history files, supplemented by Wave 13 information relating to current occupations and occupations since Wave 12. As can be seen in Table 1, 59.5 per cent of individuals in the sample examined in this paper had had a service class occupation. At first sight, this value seems rather high. Evans and Mills (2000: 647) report a value of 41 per cent for current occupations, based on 1996 Office for National Statistics Omnibus survey data. A comparable value constructed from the 2003/4 BHPS Wave 13 data is 45.9 per cent. Thus the difference between highest class and current class is crucial to the superficially high value of 59.5 per cent; the main reason why the service class percentage for the sample analysed in this paper is higher than those for other studies focusing on similar issues is that this paper incorporates the whole of each individual's work history when determining occupational attainment, rather than just an individual's current or last occupation. 
The distinction between the service class and other occupations is arguably the most clear-cut hierarchical class distinction ${ }^{11}$, leads to two relatively evenly balanced categories, and has been used elsewhere (Lampard 1995: 719; Erikson and Jonsson 1998: 25). The cost of using it is the loss of more detailed distinctions: informed by a discussion of important internal divisions within the service class (Savage et al. 1992), Egerton kept professionals and managers separate, finding that parental education was more pertinent to attaining the former grouping (Egerton 1997: 275). Other potentially important internal distinctions relate to gender segregation within the service class and to the existence of an internal hierarchy within the service class. ${ }^{12}$

The independent variables relating to parents’ occupations were derived primarily from the questions 'Thinking back to when you were 14, what job was your father doing at that time?' and 'And what job was your mother doing when you were 14?' The data were classified according to the 11-category Goldthorpe class schema (Erikson and Goldthorpe 1993: 38-39), but in this paper four 'intermediate class' categories, specifically IIIb (lower grade routine non-manual employees in sales and services), IVa and IVb (small proprietors, artisans, etc., with and without employees), and V (lower grade technicians and manual supervisors), are aggregated, as are categories VIIa (semi-skilled and unskilled manual workers) and VIIb (agricultural workers). ${ }^{13}$ The variables thus have eight categories, including an unclassified category. Four out of nine mothers were unclassified, compared to less than a tenth of fathers. More than nine out of ten of the unclassified mothers were not working, with small proportions being deceased or having unknown occupations. Unclassified fathers were spread fairly evenly across these three possibilities. 
The independent variables relating to parents' educations reflect questions asked within Wave 13: ‘Thinking first about your father’s educational qualifications, please look at this card and tell me which best describes the type of qualifications your father gained?' and 'And thinking about your mother's educational qualifications, which best describes the type of qualifications your mother gained?' A limited choice of answers was offered: 'Did not go to school at all', 'Left school with no qualifications or certificates', 'Left school with some qualifications or certificates', 'Gained further qualifications or certificates after leaving school (e.g. an apprenticeship, nursing or teaching qualifications, City and Guilds certificates)', 'Gained a university degree or higher degree' and 'Don’t know'. All six categories of the resulting variables are used in the analyses in this paper.

The independent variable corresponding to children's education was constructed from two derived variables indicating highest academic qualification and highest educational qualification. ${ }^{14}$ The resulting composite variable has ten categories: Higher Degree, First Degree, Teaching or Nursing Qualification, HND or HNC, A level plus other Higher Qualification, O level plus other Higher Qualification, A level, O level or equivalent or Commercial Qualification or CSE plus other Higher Qualification, Other Higher Qualification, None of the preceding qualifications.

The sample

Table 1 shows the percentages of the sample falling into the categories of each of the independent variables as described above. 
Parental education data were only collected at BHPS Wave 13, hence only Wave 13 respondents are used. The Wave 13 sample size was 8,701. ${ }^{15}$ Respondents lacking data for explanatory variables $(2,089)$ were discarded. ${ }^{16}$ Respondents aged over 65 years were particularly likely to lack data for the dependent variable, and were discarded (1,325). ${ }^{17}$ Respondents aged under 25 years were substantially less likely to have attained a service class occupation, and were often still in the educational system. Furthermore, since a significant proportion of respondents aged under 28 had already been discarded, the remainder were potentially unrepresentative. Respondents aged less than 28 were therefore also discarded (330). ${ }^{18}$

Of the remaining 4,957 respondents, 240 lacked the occupational data needed for the dependent variable. However, all but one of these were not currently in paid employment, suggesting that the lack of data often reflected respondents never having been employed. ${ }^{19} \mathrm{~A}$ further 52 respondents were zero-weighted, hence the final sample size is $4,665 .^{20}$ (As indicated earlier, this final sample includes a substantial number of cases who were unclassified for one or both of the parental class variables).

\section{Modelling approach}

This paper uses binary logistic regression, in which the impacts of explanatory variables on an outcome are quantified as logarithms of odds ratios. Exponentiated parameter estimates, i.e. odds ratios, are presented, since readers may find their meaning easier to grasp. Each odds ratio corresponds to the multiplicative impact of belonging to a particular category of an explanatory variable, as compared to a 'base' 
category used as a point of reference, on the odds of ever having had a service class occupation.

Lampard (1995) carried out separate logistic regressions for women and for men, but here both are included within a single analysis. This allows interaction terms to be used as a way of checking for gender differences, such as a greater impact of the characteristics of the same-sex parent, as found in some North American studies.

Explanatory variables are added to the models sequentially, so that any overlap between the effects of different variables can be established. Model 1, which controls for age, sex, and the interaction between age and sex, is used as a starting point. ${ }^{21}$ It accounts for the relatively low rates of service class attainment for women aged 50 plus, and, in particular, 60 plus. ${ }^{22}$ Models 2 and 3 include the parental education variables and the parental class variables respectively, with Model 4 including both of these. Models 5 to 8 correspond to Models 1 to 4, with the addition of the children's qualifications variable. 


\section{Findings}

Eight models of service class attainment

Table 2 documents the models' goodness-of-fit, and Table 3 shows how this differs between various pairs of models. Changes in model fit can be used to establish, albeit crudely, the fractions of the relationships between the main explanatory variables (parents' educations, parents' classes and children's qualifications) and the dependent variable that correspond to different explanatory 'paths'. Figure 1 illustrates the way in which the overall change in model fit between Model 1 (containing none of the main explanatory variables) and Model 8 (containing all of the main explanatory variables) can be subdivided into components corresponding to the various explanatory paths, with each of these paths being represented in Figure 1 by a specific area, the size of which is proportional to the size of the component corresponding to that path. (The overall effect of parental education corresponds to a particular set of four adjacent areas, as do the overall effects of parental class and of qualifications.)

Table 4 contains the exponentiated parameter estimates from the models, allowing the impact of each set of explanatory variables to be established, both when included separately and also controlling for each other. The results for Model 2 in Table 4 show that, relative to parents with no qualifications, both a mother with any qualifications and also a father with post-school qualifications increase the odds of service class attainment. This is especially true for parents with degree level qualifications, where the odds are multiplied by 4.24 and 2.84 for mothers and fathers respectively. In addition, the odds of service class attainment are close to being 
significantly lower, being multiplied by a factor of about 0.8 , if someone does not know the qualifications of one of their parents than they are if that parent is reported as having no qualifications. ${ }^{23}$

The results for Model 3 show that the odds of service class attainment vary markedly according to both father's and mother's occupational classes, when these are included simultaneously. Having a parent with a service class occupation gives the highest odds in favour of attaining a service class occupation, particularly where the father belongs to Class I. The odds ratios comparing Classes I and VII are 6.37 for fathers and 3.58 for mothers. Having a father in some of the intermediate class categories is more advantageous than having a mother in these categories, although having either parent in Class IIIa as opposed to Class VII approximately doubles the odds of service class attainment. The number of Class IVc mothers is small, hence the corresponding effect, although apparently strong, is only of borderline statistical significance. The effects of parents' classes echo those reported by Lampard (1995), although slightly more detailed effects are evident, possibly reflecting the use of a single analysis incorporating both sexes.

The results for Model 4 show the effects of the four parental characteristics when included simultaneously. The magnitudes of the effects corresponding to parents' classes are reduced for most categories, but are still substantial; the overall pattern remains similar. The consequences of simultaneous inclusion for the effects of parents' educations are more marked; however, the effects of mother's education are still substantial. 
Table 3 shows that most of the change in fit between Models 1 and 3, corresponding to the inclusion of parents' classes, is still obtained when parents' educations have already been included, as evident from the change in fit between Models 2 and 4 (263.9 out of 482.2). Conversely, markedly less than a third of the change in fit between Models 1 and 2, corresponding to the inclusion of parents' educations, is still obtained when parents' classes have already been included, as evident from the change in fit between Models 3 and 4 (87.8 out of 306.1). Given the overlap between the explanatory impacts of the two pairs of variables, parents' classes can achieve, on their own, the vast majority of the improvement in model fit that can be achieved by the inclusion of both pairs of variables (482.2 out of 570.0). ${ }^{24}$

Nevertheless, the effect of mother's education in Model 4 as shown in Table 4, the change in model fit between Models 3 and 4 as presented in Table 3, and the difference between the pseudo R-square measures for Models 3 and 4 visible in Table 2, all indicate that mother's education has an impact on service class attainment that adds substantially to the impact of parents' classes. Furthermore, given the dependence of parents' classes on parents' educations, the effect of parents' classes incorporates a substantial indirect effect corresponding to parents' educations, and the changes in model fit between Models 1 and 2 and between Models 2 and 4 suggest that the combined direct and indirect effects of parents' educations outweigh the remainder of the effect of parents' classes (306.1 compared to 263.9). Thus it appears that service class attainment is too strongly linked to parents' educations to be justifiably examined with reference to parents’ classes alone. However, as shown later, the effects of parental education vary rather than being universal. 
The results for Model 5 in Table 4 highlight the very strong effect of qualifications on the odds of service class attainment. While the effects of degree-level qualifications are particularly striking, with a degree multiplying the odds of service class attainment by 90.97 relative to no qualifications, the multiplicative nature of the odds ratios presented in Table 4 means that the observed effects constitute a series of distinct ‘steps up’ corresponding to additional or superior qualifications, with each odds ratio being between 1.26 and 2.75 times as large as the preceding one.

The change in model fit between Models 5 and 8 (152.6) shows that adding parents' educations and classes to Model 5 still results in a substantial improvement in fit, but a comparison with the change in fit between Models 1 and 4 (570.0) shows that more than two-thirds of the original improvement (417.4 out of 570.0) can be accounted for by the children's qualifications. In particular, the contribution made by the inclusion of parents' educations diminishes markedly. While the change in fit between Models 7 and 8 (29.7) shows that including parents' educations still improves the fit of the model significantly, the $p$-value and odds ratios for father's education in Model 8, as shown in Table 4, indicate that father's education no longer has a statistically significant or easily interpretable impact. The corresponding results for mother's education suggest that a mother having qualifications still increases the odds of service class attainment, but the effect is much weaker than in Model 4. Thus the effects of parents' educations largely operate indirectly, via children's qualifications.

The change in fit between Models 6 and 8 indicates that a substantial minority of the evidence of the effect of parents' classes persists once both parents' educations and children's qualifications have been taken into account (105.3 out of 482.2). However, 
a comparison of the results for parents' classes from Models 4 and 8, as shown in Table 4, indicates that the effect of father's class in particular is weakened by the inclusion of children's qualifications in the model. Again, the effects of parents' classes appear to operate to a large extent via their children’s qualifications, but there are still substantial advantages to having parents in some of the higher classes, especially Class I when compared to Class VII: a father in Class I multiplies the odds of service class attainment by 2.62 and a mother in Class I multiplies them by 2.31 . More generally, while there are subtle differences between the sets of effects for fathers and for mothers, their magnitudes are broadly similar.

Since the change in fit between Models 6 and 8 implies that a non-negligible fraction of the relationship between parents' and children’s occupational classes cannot be explained via their respective educations, intergenerational occupational class mobility patterns cannot be viewed simply as an echo of intergenerational educational mobility patterns. Furthermore, not all of the indirect effect of parents' classes on service class attainment that operates via children's qualifications is in turn an indirect effect of parents' educations, and some of the indirect effect of parents' educations that operates via parents’ classes does not also operate via their children’s qualifications. Thus, as illustrated below, a smaller part of the relationship between parents' and children's occupational classes can be explained in terms of the relationship between their respective educations than can be explained via their educations more generally. 
The next few paragraphs establish the fractions of the relationship between parents' and children's occupational classes that correspond to different explanatory paths (as illustrated in Figure 1). The change in fit between Models 6 and 8 (105.3) constitutes the evidence of an effect of parents' classes on service class attainment which is not an indirect effect of parental education and does not operate indirectly via children's qualifications.

The change in fit between Models 2 and 6 constitutes the evidence of an effect of children's qualifications that is not an indirect effect of parental education, and the change in fit between Models 4 and 8 constitutes the evidence of an effect of children's qualifications that is not an indirect effect of their parents' educations or parents’ classes. Hence the difference between these changes $(1093.3-934.7=$ 158.6) constitutes the evidence of an effect of children's qualifications which is also an indirect effect of their parents' classes, but is not an indirect effect of their parents' educations.

The change in fit between Models 5 and 6 constitutes the evidence of an effect of parental education that does not operate indirectly via children's qualifications, and the change in fit between Models 7 and 8 constitutes the evidence of an effect of parental education that does not operate via either the children's qualifications or their parents’ classes. Hence the difference between these changes $(47.3-29.7=17.6)$ constitutes the evidence of an effect of parental education that operates via parents' classes but not via children's qualifications. 
The total amount of evidence of an effect of parents' classes on service class attainment corresponds to the change in fit between Models 1 and 3. Hence the evidence for the part of this overall parental class effect that is both an indirect effect of parents' educations and operates via children's qualifications is equal to 482.2 $(105.3+158.6+17.6)=200.7$. Thus, markedly less than half of the evidence of a relationship between parents' classes and their children’s occupational attainment (200.7 out of 482.2) reflects the relationship between their respective educations. In other words, less than half of the evidence of an intergenerational occupational class relationship can be traced back to the intergenerational educational relationship.

The above findings also show that, while the majority of the evidence of an indirect effect of parents' classes operating via children's qualifications corresponds to the part of this effect that is also an indirect effect of parents' educations (200.7 out of 359.3), a substantial proportion of the evidence corresponds to the part of this effect that is not an indirect effect of parents' educations (158.6 out of 359.3). Hence, much of the part of the relationship between parents' and children's classes that operates indirectly via children's education is not a reflection of educational inheritance.

\section{Interactions}

Model 8, which does not allow for any interactions between the effects of independent variables, apart from age and sex, is arguably over-simplistic. Gender differences in the effects of the class and education variables, like those found in North American studies, and trends over time in the effects of these variables, can be represented by their interactions with sex and age. In addition, the effects of the class and education 
variables may themselves interact: for example, the effect of mother's class may vary according to father's class.

Changes in model fit corresponding to all twenty interactions of the above types were examined. Initially, only three interactions led to statistically significant improvements in model fit. However, where an interaction involved a substantial number of degrees of freedom, an interaction effect corresponding to some of the categories of the two variables could have been obscured by a lack of interaction more generally. ${ }^{25}$ In fact, two further interactions generated significant improvements in model fit when categories within one or both of the variables involved were aggregated. Model 9 thus incorporates five additional interactions: an interaction between the effects of father's class and mother's class, a gender difference in the impact of father's class, an interaction between the effects of mother's education and children's education, and interactions between age and the effects of both parents' educations. $^{26}$

More specifically, having a father in a class other than the service class together with a mother outside the service class is associated with lower odds of service class attainment than is implied by a straightforward combination of the effects of a father and a mother with these characteristics. The odds ratios corresponding to this interaction effect are 0.507 ( $p=0.032$ ) for a mother in Classes III to VII, and 0.311 $(p<0.001)$ for an unclassified mother. To put this finding another way, once someone has one service class parent, the positive impact of their other parent being in the service class is diminished. However, for men, the additional impact of having a second parent in Class I, as compared to Class VII, is still about half of the impact of 
having one Class I parent. Hence operationalising parental class using the 'dominant' parental occupation, an approach adopted by Erikson and Jonsson (1998: 24) among others, would not have been appropriate here.

Only one significant interaction effect observed here echoes the greater impact of the same-sex parent's characteristics identified in North American studies. The positive effect of a Class I father on the odds of service class attainment is less strong for women than for men. Furthermore, the negative effect of a father in Class IVc rather than Class I is much less strong for women. For example, where the mother belongs to a class other than the service class, the odds ratios corresponding to this effect are 0.440 for women and 0.159 for men. While this gender difference is not quite statistically significant ( $p=0.068$ ), it may reflect a greater tendency for sons of Class IVc fathers than for daughters to inherit their father's class position. ${ }^{27}$

Taking into account both the interaction between the effects of father's class and mother's class and also the gender difference in the impact of father's class, father's class has relatively little effect on service class attainment among women with service class mothers. For example, the impact on the predicted odds of service class attainment of being the daughter of a service class mother and a father in Class VI or VII is as positive as the impact corresponding to having two service class parents.

Turning to the interaction between the effects of mother's and children's educations, the negative effect of having a mother with no qualifications decreases as the level of an individual's own highest qualification increases, ceasing to be negative if an individual has a degree. The positive effect of having a graduate mother appears 
specific to individuals whose own highest qualifications are above O-level but below degree-level. The two remaining interactions indicate that both parents' educations vary in impact according to an individual's age, but the trends are not clear-cut. Among younger respondents, having graduate parents seems to have been more advantageous, but having parents with no qualifications also seems to have been less disadvantageous.

\section{Unpacking the role of parents' educations}

Parents' educations are likely to add more to the explanation of service class attainment for some groups of individuals than for others. More specifically, parental education may be more influential where a parent or parents are not assigned to class categories. Focusing on a combination of the direct effect of parental education on service class attainment and the indirect effect via children's qualifications only ${ }^{28}$, an examination of Model 4 applied to individuals with at least one parent not assigned to a class category shows mother's education to be of significance, with father's education having a weaker, hence statistically insignificant, impact. ${ }^{29}$ In these circumstances, having a mother with any qualifications multiplies the odds of service class attainment by $1.757(p=0.000)$ relative to having a mother with no qualifications, and having a father with qualifications multiplies them by 1.161 $(p=0.198)$. Thus parental education is of explanatory value where occupational information corresponding to one or both parents is absent. 
When class information is available for both parents, the effect of parental education instead relates primarily to the distinction between individuals who know both their parents' qualifications and those who do not. In these circumstances, not knowing a parent's qualifications reduces the odds of service class attainment relative to having a parent with no qualifications, multiplying the odds by a factor of about $0.6(p<0.05)$. Beyond this, the only further effect is that having a mother with qualifications multiplies the odds of service class attainment by $1.363(p=0.008)$. The negative impact of not knowing a parent's qualifications, relative to having a parent with no qualifications, may be rooted in family structure, the nature of the relevant parentchild relationship, or the relevant parent's perception of the value of educational qualifications.

The effects of unknown parental qualifications may have led to an over-estimation of the ability of educational inheritance to explain social mobility patterns. Restricting attention to individuals for whom each parent has a known level of qualifications, and can also be assigned to a class category, has an impact on the proportion of the relationship between parents' classes and children's occupational attainment which is attributable to the relationship between their educations, reducing it from more than two-fifths to almost exactly a third. Hence, where full information about parental characteristics is available, educational mobility has even less power to explain social mobility. ${ }^{30}$ 


\section{Discussion}

This section starts with a general consideration of the impact of parental characteristics on service class attainment. This paper has reiterated that the analysis of service class attainment cannot justifiably be carried out solely with reference to father's occupation, since mother's occupation also has a significant impact. Furthermore, parental education, particularly mother's education, has an impact, especially where parental occupational information is lacking. However, the increase in explanatory power provided by parental education is quite limited where both parents’ occupations (when an individual was 14) are known, and more detailed parental occupational histories might reduce the scope for parental education to compensate for an absence of parental occupational information. Thus, this paper's findings do not necessarily invalidate examinations of intergenerational mobility that conceptualise origins and destinations solely in terms of parents' and children’s occupational classes, if they utilize detailed occupational histories and take both parents' classes into consideration. Conversely, future studies using more detailed or reliable parental qualification data, or a wider range of educational measures, might confirm the explanatory value of supplementing parental class measures with information on parents' educations. ${ }^{31}$

Only limited evidence is provided by this paper that mothers' and fathers' occupational and educational characteristics have different implications for daughters and sons. Specifically, father's occupational class appears less influential for daughters, especially where the mother is in the service class, or where the father is a farmer or smallholder (Class IVc). However, the paper provides evidence that parental 
characteristics, particularly mother's education, vary in impact in other ways. For example, the impact of mother's education has been found to vary according to their child's own education, and to vary over time. The trends identified in the direct effect of parental education suggest that there may be a shifting relationship between educational levels and the typical underlying characteristics of parents attaining qualifications at each level. Specifically, parental characteristics that increase children's chances of service class attainment, which once were spread across a range of educational levels, may now be more concentrated within the growing category of graduate parents.

This discussion now turns to a more general account of the relationship between education and class, starting with a consideration of the specific importance of educational inheritance. This paper has shown that a relatively small proportion of the relationship between parents’ classes and children's chances of attaining a service class occupation can be accounted for by the underlying relationship between parents' and children's educations. Thus, intergenerational class mobility patterns do not simply echo intergenerational educational mobility patterns. However, trends in educational inheritance may nevertheless have a substantial impact on trends in class mobility. Hence future research would benefit from greater attention to educational mobility patterns, and more conceptually sophisticated analyses of the nature and implications of such patterns would be useful.

Of course, education does not just act as a vehicle for the transmission of parental advantage. It can be seen from Figure 1 that more than two-thirds of the evidence of the impact of children's qualifications on the odds of service class attainment (934.7 
out of 1352.1) does not relate to the indirect effects of parents' classes and educational levels. Thus it is evident that education is to a large extent a determinant of class in its own right.

The indirect effect of parental class on service class attainment operating via education can be interpreted as reflecting differential parental resources and investment in children, highlighting in particular the way in which such resources may be 'converted' into educational credentials (Goldthorpe 2000; Devine 2004). This paper has shown that a substantial proportion of this indirect effect is not simultaneously an indirect effect of parental education. Consequently, education can be seen to be, in part, a direct consequence of (parental) class, rather than simply being an indirect consequence of parental education; this may reflect economic resources linked to parental class being used to 'buy’ educational credentials. A further implication of the above finding is that interpreting all of the indirect effect of parental class via education as reflecting the intergenerational transmission of cultural capital only makes sense if parental education is viewed as an inadequate proxy for parental cultural capital and parental class is viewed as being, to a substantial extent (and in its own right), a measure of parental cultural capital.

The direct effect of parents' classes on their children's occupational attainment may also reflect the influence of parents' socio-economic resources as much as, or more than, it reflects the influence of parental cultural capital. In this context it is worth noting that only a small minority of this direct effect is in turn an indirect effect of parental education (see Figure 1). De Graaf and Kalmijn (2001: 65) suggest that the economic dimension of father's occupation has grown in empirical importance and 
also suggest that education has become 'less the domain of the cultural elite'. This paper's findings might similarly be interpreted as indicating that parental class influences educational and occupational attainment in a way that relates at least as much to the availability and impact of resources, assets and capital viewed in broad terms (Savage et al. 2005: 39) as it does to the intergenerational transmission of cultural capital more specifically.

This paper suggests that most of the effect of parental class operates via education, and that the majority of this indirect effect is in turn an indirect effect of parental education. Given that no trends relating to the direct effects of parental class or of an individual's own education were identified in this paper ${ }^{32}$, the extent of the ‘conversion’ of parental class into educational credentials (acting, in part, as a mechanism allowing parents to pass on the advantages that their own educational credentials gave them in terms of occupational attainment) must have been crucial to the presence or absence of any trends in intergenerational class mobility. Building upon the research of authors such as Devine (2004) to achieve a more developed understanding of the processes that enable education to act as a vehicle for the intergenerational transmission of cultural and economic status thus seems to be an objective of considerable importance for future studies.

As illustrated by Figure 1, a substantial minority of the overall evidence of the impact of parents' classes and educations on the odds of service class attainment (200.7 out of 570.0) relates to the part of the indirect effect of parental class operating via education which is also an indirect effect of parental education. There is thus quite substantial evidence of a process of intergenerational reproduction of advantage in 
relation to which the distinction between educational inheritance and (occupational) class reproduction is, in a sense, redundant, since the process in question can be linked to both of these. This process may reflect the intergenerational transmission of cultural capital, or of a form of educational capital of which both educational qualifications and occupational class are good indicators. Since this process can be viewed as a process of 'class reproduction', education, like occupation, can in consequence be interpreted as an integral aspect of 'class', at least when the concept is defined in this way.

In addition to the process discussed in the previous paragraph, two other effects might be interpreted as relating primarily to the intergenerational transmission of cultural capital, namely the indirect effect of parents' educations on their children's occupational attainment which operates via the children's qualifications but not via the parents' classes, and the direct effect of parents' educations on their children's occupational attainment. Together, these three explanatory pathways account for about half of the evidence corresponding to the impact of parents' educations and classes on service class attainment. Thus it can be argued that the intergenerational transmission of cultural capital, to a large extent via children’s educational attainment, plays an important role in class reproduction. However, an equally substantial proportion of the evidence appears more consistent with parental economic resources playing a crucial role in class reproduction, to some extent in the form of the direct transmission of economic advantage, but to a greater extent via the conversion of economic resources into educational credentials. 
It is important to recognise that this paper's analyses are limited in generality by their focus on service class attainment as opposed to occupational attainment more generally. The relevance of educational inheritance to occupational attainment might be expected to vary between different groups within the service class (for example, managers and professionals); the same is likely to be true for the remainder of the class structure, given variations between different occupations in the relevance of educational credentials. ${ }^{33}$ Hence analyses using a more disaggregated dependent variable would provide a wider-ranging picture of the relevance of educational inheritance and of parental characteristics more generally. Furthermore, disaggregating the dependent variable used in this paper in a way that took account of the gendered nature of occupations within the service class might reveal additional gender differences in patterns of occupational attainment. This paper has also paid limited attention to the significance of change over time; occupational and educational changes in Britain during the latter part of the $20^{\text {th }}$ Century make a more detailed examination of trends a desirable extension of the analyses presented here. ${ }^{34}$ This paper's findings might thus act as a useful starting point for elaborations of the above sort. $^{35}$

\section{Acknowledgements}

The author would like to acknowledge the helpful feedback and suggestions relating to earlier versions of this paper that were provided by the anonymous reviewers for Sociological Research Online and a number of other individuals. 


\section{Notes}

${ }^{1}$ The terms ‘occupational class mobility’ and ‘educational mobility’ are here used as a form of shorthand for the relationships between parents’ and children’s occupational classes and between parents' and children's educational levels. In other words, the focus of the paper is on parent/child relationships in general, rather than just on individuals who have been upwardly or downwardly mobile.

${ }^{2}$ A similar argument, although not necessarily equally convincing, might justify the incorporation of father's education.

${ }^{3}$ Gershuny makes the important point that a desirable property of an indicator of social position is that it links all the population to locations within the social structure, rather than just the working population (Gershuny 2000: 64).

${ }^{4}$ Devine has made the useful point that both Goldthorpe and Bourdieu appear to ascribe relatively little importance to the role of social resources in the reproduction of advantage, thus arguably under-estimating their significance in this context (Devine 2004: 182).

${ }^{5}$ Sometimes such crudities reflect the data source used: Bond and Saunders, like Egerton, used 1958 birth cohort (NCDS) data, partly explaining their variables’ limitations. Elsewhere, parental education has been operationalized as a measure of level attained, in terms either of qualifications or 'virtual years of education', i.e. the minimum number required to reach an individual's highest level of study (Sieben and De Graaf 2001: 447). 
${ }^{6}$ Egerton's operationalizations of qualifications and of father's class lacked detail within the lower educational and occupational strata, so parents’ educations may have acted as proxies for differences in class origins and qualifications at that level.

${ }^{7}$ Gunn (2005: 62) discusses institutionalised educational credentials' role in the reproduction of cultural capital.

${ }^{8}$ In addition to the educational mobility studies that have focused upon educational achievements, Halsey et al. (1980: 75) focused upon type of school.

${ }^{9}$ University of Essex, Institute for Social and Economic Research. British Household Panel Survey; Waves 1-13, 1991-2004 [computer file]. Colchester, Essex: UK Data Archive [distributor], April 2005. SN: 5151.

Halpin, B. British Household Panel Survey Combined Work-Life History Data, 19902003 (4th Edition) [computer file]. Colchester, Essex: UK Data Archive [distributor], October 2004. SN: 3954.

${ }^{10}$ Using 'highest' class rather than the class of an individual's current (or last) occupation takes account of downwards intragenerational mobility, especially (but not only) by women (Lampard 1995: 722).

${ }^{11}$ It is evident that Goldthorpe (2000: 248-250) views the service class (taken as a whole) as a relevant entity when analyzing intergenerational mobility; more specifically, he states that it "appears capable of conferring the greatest degree of advantage as a class of origin” (Goldthorpe 2000: 240).

${ }^{12}$ Crompton (2000: 167-168) notes that the growth in the representation of women in professional and managerial occupations in the latter part of the $20^{\text {th }}$ Century reflected 
existing patterns of gender segregation, with the increase being concentrated within 'service-type' aspects of management and the professions. However, she also relates the "gendered restructuring of the middle classes" to the professional/managerial distinction (Crompton 2000: 178-179). Marshall et al. (1997: 106-132) use the service class (“salariat”) within their intergenerational mobility analyses, but break it down into "higher" and "lower” parts (i.e. Goldthorpe classes I and II), to the extent that their sample size makes this possible. Devine (2004: 195) also views this hierarchical distinction as of potential importance.

${ }^{13}$ For both parents, these categories could be aggregated without a statistically significant deterioration in the fit of Models 3 and 8. Class IVc (farmers/smallholders) and the unclassified category could also have been aggregated with other categories without a significant deterioration in model fit, but have been kept separate for conceptual reasons.

14 The latter variable, with twelve categories to the former's seven, incorporates a broader range of qualifications but also includes a heterogeneous 'Other higher qualification' category. The derivation of the composite variable, and the aggregation of categories leading to its finalized form, made use of the proportions of individuals within categories who had attained service class occupations.

${ }^{15}$ Data from additional samples of households in Wales and Scotland (which were added to the main BHPS sample in 1999) and from an additional sample of households in Northern Ireland (which was added in 2001) are not used.

${ }^{16}$ For most of these $(1,348)$, the design of the BHPS meant that data had not been collected for the parental class variables. Some other respondents (122) lacked data 
for these variables for other reasons. For some of the remainder (437), proxy respondents supplied Wave 13 data, resulting in missing data for respondents' and parents' educations. A further subset lacked data for the highest qualification variables.

${ }^{17}$ This partly reflects the approach to collecting employment histories used by the BHPS.

${ }^{18}$ The proportion of young respondents whose occupational histories had peaked was bound to be relatively low. A lower bound of 28 still implies an under-estimation of the rate of service class attainment of younger respondents, but the observed proportions suggest that the extent of this is unproblematic.

${ }^{19}$ Most of these respondents (175) were women, about half (87) of whom were engaged in 'family care'. A substantial minority (81) were affected by long-term sickness or disability. The remainder were mainly retired (50), or unemployed (19).

${ }^{20}$ The data are weighted, as the BHPS documentation recommends for cross-sectional analyses, by MXEWGHT, adjusted to maintain the overall sample size, since the weights for the 4,665 respondents only totalled 4,591.72.

${ }^{21}$ The impact of age was modelled in an effective way using ten-year age bands: 2829, 30-39, 40-49, etc. Since age, sex and their interaction were included primarily as controls, corresponding sets of exponentiated parameter estimates, for a subset of models only, are presented in Table 5.

${ }^{22}$ In Model 8, age, sex and their interaction instead take account of relatively high rates of service class attainment for men aged 50 plus, and, in particular, 60 plus, 
controlling for qualifications and parental characteristics (see Table 5). The majority of this shift occurs between Models 1 and 5, suggesting that the ability of men with a given level of qualifications to attain the service class has been affected by a rapid rise in qualification levels within the population, relative to the slower expansion of the service class. However, for women, something appears to have compensated for this effect, leading to a reduction in gender inequality.

${ }^{23}$ Sullivan (2001: 907) reported missing parental qualifications as affecting educational attainment negatively.

${ }^{24}$ The ways in which the decompositions of changes in model fit in this and subsequent paragraphs relate to different explanatory paths can be seen in graphical form in Figure 1.

${ }^{25}$ A statistically significant change in model fit may not remain significant when combined with a second change in fit of a magnitude similar to its number of degrees of freedom.

${ }^{26}$ There is scope here only for a summary discussion of these interaction effects, hence exponentiated parameter estimates from Model 9 are not presented.

${ }^{27}$ Erikson and Jonsson (1998) report a similar finding for Sweden.

${ }^{28}$ In other words, the combined effect in question excludes the indirect effect of parental education that operates via both parental class and also children's qualifications. 
${ }^{29}$ Korupp et al. (2002: 33) found that mother's education was more important to children's educational attainment if the mother was a 'home-maker' than if she was employed.

${ }^{30}$ Restricting the analysis to individuals for whom full information about parental characteristics is available is in effect adopting the 'listwise deletion' approach to dealing with missing data (Allison 2001: 6). The earlier analyses adopt an approach which more closely resembles ‘dummy variable adjustment' (Allison 2001: 9). In some situations the listwise deletion approach is preferable; however, where missing data is not "missing at random (MAR)", both approaches are potentially problematic (Allison 2001: 4-11). With regard to the analyses in this paper, it is evident from the distinctive (and relatively extreme) parameter estimates from Models 2 and 3 corresponding to the categories relating to unknown information about parents' classes and educations (see Table 4) that the 'missing' data are not 'missing at random'. This also highlights the crucial point that these 'missing data' categories do not necessarily have to be interpreted as such. As reported earlier, the vast majority of parents who were unclassified for parental class did not have an occupation at the relevant point in time. Where parents' educations are unknown, this seems likely in many or most cases to reflect parental absence or, perhaps, a lack of qualifications for the child to know about. In situations where an unobserved value simply does not exist, dummy variable adjustment may be an appropriate approach (Allison 2001: 10, 87). Perhaps more to the point, if categories corresponding to data which are superficially missing can be seen as relating to (sets of) situations that can be assumed to be qualitatively different to the situations defining the other categories, then the standard missing data issues do not appear to be of relevance, although the process of 
interpretation may not be straightforward. While the afore-mentioned assumption is not entirely correct in the context of this paper, it nevertheless comes close to being a reasonable assumption.

${ }^{31}$ See Erikson and Jonsson (1998: 21). In addition, Kerckhoff et al. (1982: 360) found that secondary school type had an impact on occupational attainment in Britain.

${ }^{32}$ The relative abilities of different levels of qualifications to provide access to the service class thus appear stable.

${ }^{33}$ Furthermore, the loss of detail inherent in focusing upon service class attainment may have implications for the observed balance of explanatory importance between parental class and parental education.

${ }^{34}$ A specific issue of relevance in this context is the fact that the analyses in this paper do not focus upon the relative meanings of occupations or levels of education when compared to all other occupations or educational levels. Since the analyses involve the occupations and education levels of individuals of a range of ages, and also the occupations and educations of their parents, and given the changes in occupational and educational distributions that took place in the $20^{\text {th }}$ Century (which, in addition, were different for women and men), the relative meaning of a specific occupation or educational level is unlikely to be consistent across the various individuals and parents present within the analyses in this paper who have that occupation or educational level. Arguably, if one is not prepared to assume that the meanings of occupations and educational levels do not vary between cohorts, a process of standardization should be applied to the occupational and educational distributions for different cohorts. Such an approach is quite frequently used in studies examining 
trends in social mobility or related phenomena (Lambert et al. 2007: 2.18; Lampard 2000), but is not seen as necessary or appropriate by all researchers working in the fields of occupational attainment and social mobility. In this paper, the attention that is paid to interactions between age and the independent variables relating to occupation and education goes some way towards taking account of the scope for changes in the relative meanings of categories within these independent variables to have an impact on the paper's findings. (See, for example, Note 32).

35 The findings for categories corresponding to parents whose occupations or educations could not be classified or were unknown also suggest that examining variations in the impact of parental characteristics according to family structure would be valuable (distinguishing between lone-parent families, stepfamilies and other forms of family). Given the changing prevalence of different family forms in Britain over recent decades, any variations of this sort must have contributed to overall trends in the impact of parental characteristics. 


\section{Bibliography}

ALLISON, P. D. (2001) Missing Data, Sage University Papers Series on Quantitative Applications in the Social Sciences, Series No. 07-136. Thousand Oaks, CA: Sage. BECKER, G. and TOMES, N. (1986) 'Human capital and the rise and fall of families', Journal of Labor Economics, Vol. 4, pp. S1 - S39.

BLAU, P. M. and DUNCAN, O. D. (1967) The American Occupational Structure. New York: Wiley.

BOND, R. and SAUNDERS, P. (1999) 'Routes of success: influences on the occupational attainment of young British males’, British Journal of Sociology, Vol. 50, No. 2, pp. 217 - 249.

BOURDIEU, P. (1973) ‘Cultural Reproduction and Social Reproduction’, in R. K. Brown (editor) Knowledge, Education and Cultural Change. London: Tavistock. BOURDIEU, P. (1984) Distinction. London: Routledge and Kegan Paul. [First published in 1979].

BOURDIEU, P. (1997) 'The Forms of Capital’, in A. H. Halsey, H. Lauder, P. Brown and A. S. Wells (editors) Education: Culture, Economy, Society. Oxford: Oxford University Press.

BREEN, R. and JONSSON, J. O. (2005) 'Inequality of Opportunity in Comparative Perspective: Recent Research on Educational Attainment and Social Mobility’, Annual Review of Sociology, Vol. 31, pp. 223 - 243.

CHEVALIER, A., DENNY, K. and McMAHON, D. (2003) A Multi-Country Study of Inter-Generational Educational Mobility, UCD Centre for Economic Research Working Paper WP03/14. Dublin: University College Dublin. 
CHEVALIER, A. and LANOT, G. (2002) 'The relative effect of family characteristics and financial situation on educational achievement', Education Economics, Vol. 10, pp. 165 - 181.

COMI, S. (2003) Intergenerational mobility in Europe: evidence from ECHP, Paper presented at the European Panel Users’ Network conference, Colchester, July 2003. COX, D. R. and SNELL, E. J. (1989) Analysis of binary data (2nd edition). London: Chapman and Hall.

CROMPTON, R. (1998) Class and Stratification. Cambridge: Polity Press.

CROMPTON, R. (2000) 'The gendered restructuring of the middle classes:

employment and caring', in R. Crompton, F. Devine, M. Savage and J. Scott (editors) Renewing Class Analysis. Oxford: Blackwell/The Sociological Review.

CROMPTON, R. (2006) 'Class and family’, Sociological Review, Vol. 54, No. 4, pp. $658-677$.

CROMPTON, R. and SCOTT, J. (2000) 'Introduction: the state of class analysis', in R. Crompton, F. Devine, M. Savage and J. Scott (editors) Renewing Class Analysis. Oxford: Blackwell/The Sociological Review.

DE GRAAF, N. D., DE GRAAF, P. M. and KRAAYKAMP, G. (2000) 'Parental cultural capital and educational attainment in the Netherlands: A refinement of the cultural capital perspective', Sociology of Education, Vol. 73, No. 2, pp. 92 - 111. DE GRAAF, P. M. and KALMIJN, M. (2001) 'Trends in the intergenerational transmission of cultural and economic status', Acta Sociologica, Vol. 44, No. 1, pp. $51-66$.

DEARDEN, L., MACHIN, S. and REED, H. (1997) 'Intergenerational Mobility in Britain', The Economic Journal, Vol. 107, No. 440, pp. 47 - 66. 
DEVINE, F. (1998) 'Class Analysis and the Stability of Class Relations', Sociology, Vol. 32, No. 1, pp. 23 - 42.

DEVINE, F. (2004) Class Practices: How Parents Help Their Children Get Good Jobs. Cambridge: Cambridge University Press.

DEVINE, F. and SAVAGE, M. (2000) 'Conclusion: renewing class analysis', in R. Crompton, F. Devine, M. Savage and J. Scott (editors) Renewing Class Analysis. Oxford: Blackwell/The Sociological Review.

EGERTON, M. (1997) 'Occupational inheritance: The role of cultural capital and gender', Work, Employment and Society, Vol. 11, No. 2, pp. 263 - 282.

ERIKSON, R. and GOLDTHORPE, J. H. (1993) The Constant Flux: A Study of Class Mobility in Industrial Societies. Oxford: Clarendon Press.

ERIKSON, R. and JONSSON, J. O. (1998) 'Social Origin as an Interest-bearing Asset: Family Background and Labour-market Rewards among Employees in Sweden’, Acta Sociologica, Vol. 41, No. 1, pp. 19 - 36.

EVANS, G. and MILLS, C. (2000) 'In search of the wage-labour/service contract: new evidence on the validity of the Goldthorpe class schema', British Journal of Sociology, Vol. 51, No. 4, pp. 641 - 661.

GERSHUNY, J. 2000. 'Social position from narrative data’, in R. Crompton, F.

Devine, M. Savage and J. Scott (editors) Renewing Class Analysis. Oxford:

Blackwell/The Sociological Review.

GOLDTHORPE, J. H. (1996) ‘Class Analysis and the Reorientation of Class Theory’, British Journal of Sociology, Vol. 47, No. 3, pp. 481 - 505.

GOLDTHORPE, J. H. (2000) On Sociology: Numbers, Narratives, and the Integration of Research and Theory. Oxford: Oxford University Press. 
GOLDTHORPE, J. H., LLEWELLYN, C. and PAYNE, C. (1987) Social Mobility and Class Structure in Modern Britain (2nd edition). Oxford: Clarendon Press.

GUNN, S. (2005) 'Translating Bourdieu: cultural capital and the English middle class in historical perspective', British Journal of Sociology, Vol. 56, No. 1, pp. 49 - 64. HALPIN, B. (1997) Unified BHPS work-life histories: combining multiple sources into a user-friendly format, Technical Papers of the ESRC Research Centre on MicroSocial Change, No. 13. Colchester: University of Essex.

HALSEY, A. H., HEATH, A. F. and RIDGE, J. M. (1980) Origins and Destinations: Family, Class and Education in Modern Britain. Oxford: Clarendon Press.

HAYES, B. C. and MILLER, R. L. (1989) 'Intergenerational Occupational Mobility within the Republic of Ireland: The Ignored Female Dimension', Women’s Studies International Forum, Vol. 12, No. 4, pp. 439 - 445.

HAYES, B. C. and MILLER, R. L. (1993) 'The silenced voice: female social mobility patterns with particular reference to the British Isles’, British Journal of Sociology, Vol. 44, No. 4, pp. 653 - 672.

JÆGER, M. M. and HOLM, A. (2003) Which factors matter more in intergenerational educational attainment: Social class, cultural capital or cognitive ability? A random effects approach, Centre for Applied Microeconometrics Working Paper 2003-05. Copenhagen: University of Copenhagen.

JONSSON, J. O. and ERIKSON, R. (2000) 'Understanding Educational Inequality. The Swedish Experience', L'Année sociologique, Vol. 50, No. 2, pp. 345 - 382. KERCKHOFF, A. C., CAMPBELL, R. T. and TROTT, J. M. (1982) 'Dimensions of Educational and Occupational Attainment in Great Britain’, American Sociological Review, Vol. 47, No. 3, pp. 347 - 364. 
KORUPP, S. E., GANZEBOOM, H. B. G. and VAN DER LIPPE, T. (2002) ‘Do

Mothers Matter? A Comparison of Models of the Influence of Mothers' and Fathers’

Educational and Occupational Status on Children's Educational Attainment', Quality and Quantity, Vol. 36, No. 1, pp. 17 - 42.

LAMBERT, P., PRANDY, K. and BOTTERO, W. (2007) 'By Slow Degrees: Two

Centuries of Social Reproduction and Mobility in Britain', Sociological Research

Online, Vol. 12, No. 1, <http://www.socresonline.org.uk/12/1/prandy.html>.

LAMPARD, R. (1995) ‘Parents’ Occupations and Their Children’s Occupational

Attainment: A Contribution to the Debate on the Class Assignment of Families',

Sociology, Vol. 29, No. 4, pp. 715 - 728.

LAMPARD, R. (2000) 'Measuring inequality in a cross-tabulation with ordered categories: from the Gini coefficient to the Tog coefficient', International Journal of Social Research Methodology, Vol. 3, No. 1, pp. 1 - 14.

LAREAU, A. and WEININGER, E. B. (2003) 'Cultural capital in educational research: A critical assessment', Theory and Society, Vol. 32, pp. 567 - 606. MARSHALL, G., SWIFT, A. and ROBERTS, S. (1997) Against the Odds? Social Class and Social Justice in Industrial Societies. Oxford: Clarendon Press. McCLENDON, M. J. (1976) 'The Occupational Status Attainment Processes of Males and Females’, American Sociological Review, Vol. 41, No. 1, pp. 52 - 64.

MILLER, R. L. and HAYES, B. C. (1990) ‘Gender and Intergenerational Mobility’, in G. Payne and P. Abbott (editors) The Social Mobility of Women: Beyond Male Mobility Models. Basingstoke: Falmer Press.

PAYNE, G. (1987). Employment and Opportunity. Basingstoke: Macmillan.

PEARSON, J. (1983) 'Mothers and Daughters: Measuring Occupational Inheritance’, Sociology and Social Research, Vol. 67, No. 2, pp. 204 - 217. 
ROSENFELD, R. A. (1978) 'Women’s Intergenerational Occupational Mobility’, American Sociological Review, Vol. 43, No. 1, pp. 36 - 46.

SAVAGE, M., BARLOW, J., DICKENS, P. and FIELDING, T. (1992) Property, Bureaucracy and Culture: Middle Class Formation in Contemporary Britain. London: Routledge.

SAVAGE, M., WARDE, A. and DEVINE, F. (2005) 'Capitals, assets, and resources: some critical issues’, British Journal of Sociology, Vol. 56, No. 1, pp. 31 - 47.

SIEBEN, I. and DE GRAAF, P. M. (2001) 'Testing the modernization hypothesis and the socialist ideology hypothesis: a comparative sibling analysis of educational attainment and occupational status', British Journal of Sociology, Vol. 52, No. 3, pp. $441-467$.

SIEBEN, I. and DE GRAAF, P. M. (2003) 'The Total Impact of the Family on Educational Attainment: a Comparative Sibling Analysis’, European Societies, Vol. 5, No. 1, pp. 33 - 68 .

STEVENS, G. (1986) ‘Sex-Differentiated Patterns of Intergenerational Occupational Mobility', Journal of Marriage and the Family, Vol. 48, No. 1, pp. 153 - 163.

SULLIVAN, A. (2001) 'Cultural capital and educational attainment', Sociology, Vol. 35, No. 4, pp. 893 - 912.

TREIMAN, D. J. and TERRELL, K. (1975) 'Sex and the Process of Status Attainment: A Comparison of Working Women and Men’, American Sociological Review, Vol. 40, No. 2, pp. 174 - 200.

ULTEE, W. and LUIJKX, R. (2003) Did Downward Mobility Decrease Because of Governmental Measures Enhancing Upward Mobility? Changes in the Netherlands during the 20th Century, Paper presented at a meeting of the ISA Research Committee on Social Stratification and Mobility (RC28), New York, August 2003. 
WARREN, J. R., HAUSER, R. M. and SHERIDAN, J. T. (2002) 'Occupational Stratification across the Life Course: Evidence from the Wisconsin Longitudinal Study', American Sociological Review, Vol. 67, No. 3, pp. 432 - 455.

WESTERN, M. (1999) 'Class Attainment among British Men: A Multivariate

Extension of the CASMIN Model of Intergenerational Class Mobility’, European

Sociological Review, Vol. 15, No. 4, pp. 431 - 454. 
Table 1: Frequencies for the dependent variable and the independent variables used in the logistic regression models of service class attainment.

\begin{tabular}{|c|c|c|}
\hline Variable & Category & $\underline{\text { Frequency }}$ \\
\hline \multirow{2}{*}{$\begin{array}{l}\text { Highest class } \\
\text { attained }\end{array}$} & Service class & $2774(59.5)$ \\
\hline & Not service class & $1891(40.5)$ \\
\hline \multirow[t]{5}{*}{ Age } & $28-29$ & 214 \\
\hline & $30-39$ & $1321(28.3)$ \\
\hline & $40-49$ & 1331 (28.5) \\
\hline & $50-59$ & $1241(26.6)$ \\
\hline & $60-65$ & $558(12.0)$ \\
\hline \multirow[t]{2}{*}{ Sex } & Men & $2160(46.3)$ \\
\hline & Women & $2505(53.7)$ \\
\hline \multirow{6}{*}{$\begin{array}{l}\text { Father's } \\
\text { qualifications }\end{array}$} & Don’t know & 508 (10.9) \\
\hline & Did not go to school & 59 (1.3) \\
\hline & No qualifications & $1933(41.4)$ \\
\hline & Some qualifications & 727 (15.6) \\
\hline & Further qualifications & $1153(24.7)$ \\
\hline & Degree & $285(6.1)$ \\
\hline \multirow{6}{*}{$\begin{array}{l}\text { Mother's } \\
\text { qualifications }\end{array}$} & Don’t know & 408 (8.7) \\
\hline & Did not go to school & 66 (1.4) \\
\hline & No qualifications & 2277 (48.8) \\
\hline & Some qualifications & 1100 (23.6) \\
\hline & Further qualifications & $652(14.0)$ \\
\hline & Degree & 163 (3.5) \\
\hline \multirow{8}{*}{$\begin{array}{l}\text { Father's } \\
\text { class }\end{array}$} & I & $679(14.6)$ \\
\hline & II & $429 \quad(9.2)$ \\
\hline & IIIa & 171 (3.7) \\
\hline & IIIb/IVa\&b/V & $1140(24.4)$ \\
\hline & IVc & $97(2.1)$ \\
\hline & VI & 743 (15.9) \\
\hline & VII & $961(20.6)$ \\
\hline & Unclassified & $446 \quad(9.6)$ \\
\hline \multirow{8}{*}{$\begin{array}{l}\text { Mother's } \\
\text { class }\end{array}$} & I & $95 \quad(2.0)$ \\
\hline & II & 411 (8.8) \\
\hline & IIIa & $477(10.2)$ \\
\hline & IIIb/IVa\&b/V & $663(14.2)$ \\
\hline & IVc & $16(0.3)$ \\
\hline & VI & 161 (3.5) \\
\hline & VII & 767 (16.4) \\
\hline & Unclassified & 2075 (44.5) \\
\hline
\end{tabular}


Table 1 (continued): Frequencies for the dependent variable and the independent variables used in the logistic regression models of service class attainment.

$\underline{\text { Variable }}$

Own qualifications

\section{Category}

Higher degree

Degree

Teaching/Nursing qualification HNC or HND

A level plus other higher qual.

O level plus other higher qual.

A level

O level/equivalent/Commercial qual.

Other higher qualification

None of the above qualifications

\section{Frequency}

161 (3.4)

$611(13.1)$

183 (3.9)

$236 \quad(5.1)$

$472(10.1)$

$488(10.5)$

$457 \quad(9.8)$

963 (20.6)

$217 \quad(4.6)$

$878(18.8)$

\section{Notes:}

$\mathrm{n}=4,665$. The figures in parentheses are percentages. The data are weighted (as described in Note 20), hence the frequencies for a variable do not necessarily sum to the overall sample size, because of rounding. 
Table 2: Goodness-of-fit of logistic regression models of service class attainment.

\begin{tabular}{|c|c|c|c|c|c|}
\hline Model & Terms included in the model & $\begin{array}{l}-2 \text { Log } \\
\text { Likelihood } \\
\end{array}$ & $\begin{array}{l}\text { Model } \\
\text { Chi-square }\end{array}$ & d.f. & $\begin{array}{l}\text { Pseudo } \\
\text { R-square }\end{array}$ \\
\hline Model 1 & Base (Age, Sex, Age by Sex) & $6,240.3$ & 58.3 & 9 & 0.012 \\
\hline Model 2 & + PEDUC & $5,934.2$ & 364.4 & 19 & 0.075 \\
\hline Model 3 & + PCLASS & $5,758.1$ & 540.5 & 23 & 0.109 \\
\hline Model 4 & + PEDUC + PCLASS & $5,670.3$ & 628.3 & 33 & 0.126 \\
\hline Model 5 & + EDUC & $4,888.1$ & $1,410.4$ & 18 & 0.261 \\
\hline Model 6 & + PEDUC + EDUC & $4,840.8$ & $1,457.7$ & 28 & 0.268 \\
\hline Model 7 & + PCLASS + EDUC & $4,765.2$ & $1,533.3$ & 32 & 0.280 \\
\hline Model 8 & + PEDUC + PCLASS + EDUC & $4,735.5$ & $1,563.0$ & 42 & 0.285 \\
\hline Model 9 & Model 8 + Interaction terms & $4,651.0$ & $1,647.6$ & 62 & 0.298 \\
\hline
\end{tabular}

Notes:

PEDUC $=$ Parents' education variables; PCLASS = Parents' class variables; EDUC = Children's qualifications variable; d.f. = Degrees of freedom . $p<0.001$ for the Model Chi-square of each of the models.

For a discussion of the Pseudo R-square measure, see Cox and Snell (1989). 
Table 3: Changes in fit (-2 Log Likelihood) between logistic regression models of service class attainment (see Table 2)

$\begin{array}{lrrrrr}\text { Model } & 2 & 3 & 4 & 5 & \\ 1 & 306.1(10) & 482.2(14) & 570.0(24) & 1,352.2 \quad(9) \\ 2 & & & 263.9(14) & & \\ 3 & & & 87.8(10) & \end{array}$

$\begin{array}{lllll}\text { Model } & 6 & 7 & 8 & 9\end{array}$

$\begin{array}{lrrrr}1 & 1,399.4(19) & 1,475.0(23) & 1,504.7(33) \\ 2 & 1,093.3(9) & & 1,198.6(23) \\ 3 & & & 992.8 \quad(9) & 1,022.5(19) \\ 4 & & & 934.7 \quad(9) \\ 5 & & & 152.6(24) \\ 6 & 47.3(10) & 122.9(14) & 105.3(14) \\ 7 & & & 29.7(10) & \\ 8 & & & & 84.6(20)\end{array}$

Notes:

The figures in parentheses are changes in numbers of degrees of freedom. The changes in model fit are all statistically significant, with $p<0.01$ in each case. However, father's education can be removed from Models 4, 6 and 8 without a significant deterioration in the fit of these models $(p>0.05)$. 
Table 4: Exponentiated parameter estimates (odds ratios) from logistic regression models of service class attainment (see Table 2).

\begin{tabular}{|c|c|c|c|c|}
\hline Variable & Category & Model 2 & Model 3 & Model 4 \\
\hline \multirow{6}{*}{$\begin{array}{l}\text { Father's } \\
\text { quals }\end{array}$} & Don't know & $0.79(0.056)$ & & $0.80(0.086)$ \\
\hline & No school & $1.41(0.301)$ & & $1.41(0.318)$ \\
\hline & No quals & $1.00(\mathbf{0 . 0 0 0 )}$ & & $1.00(\mathbf{0 . 0 7 9 )}$ \\
\hline & Some quals & $1.17(0.116)$ & & $0.89(0.264)$ \\
\hline & Further quals & $1.44(0.000)$ & & 1.09 (0.359) \\
\hline & Degree & $2.84(0.000)$ & & $1.29(0.216)$ \\
\hline \multirow{6}{*}{$\begin{array}{l}\text { Mother's } \\
\text { quals }\end{array}$} & Don't know & $0.78(0.052)$ & & $0.69(0.006)$ \\
\hline & No school & $0.94(0.826)$ & & $0.91(0.751)$ \\
\hline & No quals & $1.00(\mathbf{0 . 0 0 0 )}$ & & $1.00(\mathbf{0 . 0 0 0 )}$ \\
\hline & Some quals & $1.90(0.000)$ & & $1.63(0.000)$ \\
\hline & Further quals & $1.93(0.000)$ & & $1.40(0.003)$ \\
\hline & Degree & $4.24(0.000)$ & & $2.25(0.004)$ \\
\hline \multirow{8}{*}{$\begin{array}{l}\text { Father's } \\
\text { class }\end{array}$} & $\mathrm{I}$ & & $6.37(0.000)$ & $4.89(0.000)$ \\
\hline & II & & $3.14(0.000)$ & $2.79(0.000)$ \\
\hline & IIIa & & $1.94(0.000)$ & $1.69(0.004)$ \\
\hline & IIIb/IVa\&b/V & & $1.90(0.000)$ & $1.80(0.000)$ \\
\hline & IVc & & $1.19(0.434)$ & 1.03 (0.883) \\
\hline & VI & & $1.40(0.001)$ & $1.33(0.005)$ \\
\hline & VII & & $1.00(\mathbf{0 . 0 0 0 )}$ & $1.00(\mathbf{0 . 0 0 0 )}$ \\
\hline & Unclassified & & $1.07(0.574)$ & $1.11(0.393)$ \\
\hline \multirow{8}{*}{$\begin{array}{l}\text { Mother's } \\
\text { class }\end{array}$} & $\mathrm{I}$ & & $3.58(0.000)$ & $2.82(0.001)$ \\
\hline & II & & $2.58(0.000)$ & $2.19(0.000)$ \\
\hline & IIIa & & $2.05(0.000)$ & $1.86(0.000)$ \\
\hline & IIIb/IVa\&b/V & & $1.31(0.016)$ & $1.24(0.059)$ \\
\hline & IVc & & $3.04(0.050)$ & $3.33(0.038)$ \\
\hline & VI & & $1.39(0.064)$ & $1.35(0.098)$ \\
\hline & VII & & $1.00(\mathbf{0 . 0 0 0 )}$ & $1.00(\mathbf{0 . 0 0 0 )}$ \\
\hline & Unclassified & & $1.15(0.117)$ & $1.13(0.178)$ \\
\hline
\end{tabular}

Notes:

The figures in parentheses are $p$-values. The $p$-values in bold type are adjacent to the variables' base categories, and correspond to each variable's overall significance. The remaining $p$-values correspond to comparisons between the base category for each variable and each of the other categories. 
Table 4 (continued): Exponentiated parameter estimates (odds ratios) from logistic regression models of service class attainment (see Table 2).

\begin{tabular}{|c|c|c|c|c|c|}
\hline$\underline{\text { Variable }}$ & Category & $\underline{\text { Model } 5}$ & $\underline{\text { Model } 6}$ & $\underline{\text { Model } 7}$ & $\underline{\text { Model } 8}$ \\
\hline \multirow{6}{*}{$\begin{array}{l}\text { Father's } \\
\text { quals }\end{array}$} & Don't know & & $0.91(0.453)$ & & $0.91(0.487)$ \\
\hline & No school & & $0.99(0.973)$ & & $0.99(0.988)$ \\
\hline & No quals & & 1.00 (0.197) & & $1.00(\mathbf{0 . 0 7 9})$ \\
\hline & Some quals & & $0.80(0.053)$ & & $0.70(0.002)$ \\
\hline & Further quals & & $1.07(0.497)$ & & $0.91(0.352)$ \\
\hline & Degree & & $1.17(0.470)$ & & $0.74(0.196)$ \\
\hline \multirow{6}{*}{$\begin{array}{l}\text { Mother's } \\
\text { quals }\end{array}$} & Don’t know & & $0.83(0.198)$ & & $0.76(0.067)$ \\
\hline & No school & & 1.15 (0.703) & & $1.14(0.726)$ \\
\hline & No quals & & $1.00(\mathbf{0 . 0 0 0 )}$ & & $1.00(\mathbf{0 . 0 0 0})$ \\
\hline & Some quals & & $1.59(0.000)$ & & $1.47(0.000)$ \\
\hline & Further quals & & $1.34(0.016)$ & & $1.10(0.446)$ \\
\hline & Degree & & $2.16(0.010)$ & & $1.36(0.325)$ \\
\hline \multirow{8}{*}{$\begin{array}{l}\text { Father's } \\
\text { class }\end{array}$} & I & & & $2.56(0.000)$ & $2.62(0.000)$ \\
\hline & II & & & $1.76(0.000)$ & $1.83(0.000)$ \\
\hline & IIIa & & & $0.98(0.902)$ & $0.98(0.937)$ \\
\hline & IIIb/IVa\&b/V & & & $1.57(0.000)$ & $1.59(0.000)$ \\
\hline & IVc & & & $0.71(0.211)$ & $0.66(0.138)$ \\
\hline & VI & & & $1.16(0.181)$ & $1.16(0.203)$ \\
\hline & VII & & & $1.00(\mathbf{0 . 0 0 0})$ & $1.00(\mathbf{0 . 0 0 0})$ \\
\hline & Unclassified & & & $0.99(0.950)$ & $1.03(0.814)$ \\
\hline \multirow{8}{*}{$\begin{array}{l}\text { Mother's } \\
\text { class }\end{array}$} & $\mathrm{I}$ & & & $2.33(0.015)$ & $2.31(0.018)$ \\
\hline & II & & & $1.99(0.000)$ & $1.94(0.000)$ \\
\hline & IIIa & & & $1.58(0.002)$ & $1.55(0.003)$ \\
\hline & IIIb/IVa\&b/V & & & $1.15(0.269)$ & $1.13(0.319)$ \\
\hline & IVc & & & $2.92(0.094)$ & $3.06(0.081)$ \\
\hline & VI & & & $1.65(0.011)$ & $1.63(0.014)$ \\
\hline & VII & & & $1.00(\mathbf{0 . 0 0 0 )}$ & $1.00(\mathbf{0 . 0 0 0})$ \\
\hline & Unclassified & & & $1.12(0.263)$ & $1.12(0.274)$ \\
\hline \multirow{10}{*}{$\begin{array}{l}\text { Own } \\
\text { quals }\end{array}$} & Higher degree & \multicolumn{4}{|c|}{$221.12(0.000) 175.69(0.000) 157.04(0.000) 156.78(0.000$} \\
\hline & Degree & $90.97(0.000)$ & $74.56(0.000)$ & $65.42(0.000)$ & $63.68(0.000)$ \\
\hline & Teach./Nurse & $32.97(0.000)$ & $29.39(0.000)$ & $27.21(0.000)$ & $26.44(0.000)$ \\
\hline & HNC/HND & $19.86(0.000)$ & $18.30(0.000)$ & $15.81(0.000)$ & $15.81(0.000)$ \\
\hline & A level plus & $9.52(0.000)$ & $8.64(0.000)$ & $8.13(0.000)$ & $8.04(0.000)$ \\
\hline & O level plus & $6.12(0.000)$ & $5.70(0.000)$ & $5.39(0.000)$ & $5.33(0.000)$ \\
\hline & A level & $4.84(0.000)$ & $4.48(0.000)$ & $4.05(0.000)$ & $4.05(0.000)$ \\
\hline & O level/equiv. & $3.12(0.000)$ & $2.96(0.000)$ & $2.91(0.000)$ & $2.87(0.000)$ \\
\hline & Other Higher & $2.15(0.000)$ & $2.10(0.000)$ & $2.17(0.000)$ & $2.20(0.000)$ \\
\hline & None & $1.00(\mathbf{0 . 0 0 0 )}$ & $1.00(\mathbf{0 . 0 0 0})$ & $1.00(\mathbf{0 . 0 0 0})$ & $1.00(\mathbf{0 . 0 0 0})$ \\
\hline
\end{tabular}


Table 5: Exponentiated parameter estimates (odds ratios) corresponding to age and sex (in combination) from logistic regression models of service class attainment (see Table 2).

\section{$\underline{\text { Model } 1 \quad \underline{\text { Model } 5} \quad \underline{\text { Model } 8}}$}

Men aged 28-29

$\begin{array}{lll}1.00 & 1.00 & 1.00 \\ 0.83(0.407) & 0.76(0.277) & 0.78(0.339) \\ 0.96(0.836) & 1.09(0.723) & 1.16(0.565) \\ 0.84(0.416) & 1.21(0.459) & 1.38(0.216) \\ 0.92(0.728) & 1.81(0.031) & 2.06(0.011) \\ & & \\ 0.89(0.672) & 0.79(0.467) & 0.77(0.433) \\ 0.86(0.485) & 0.88(0.595) & 0.88(0.601) \\ 0.87(0.515) & 1.09(0.728) & 1.13(0.626) \\ 0.61(0.020) & 0.95(0.848) & 1.05(0.860) \\ 0.39(0.000) & 0.73(0.256) & 0.87(0.605)\end{array}$

Notes:

The figures in parentheses are $p$-values, corresponding to comparisons between the base category (men aged 28-29) and each of the other categories. 
Figure 1: Decomposition of the change in model fit between Model 1 and Model 8 into components corresponding to different explanatory paths.

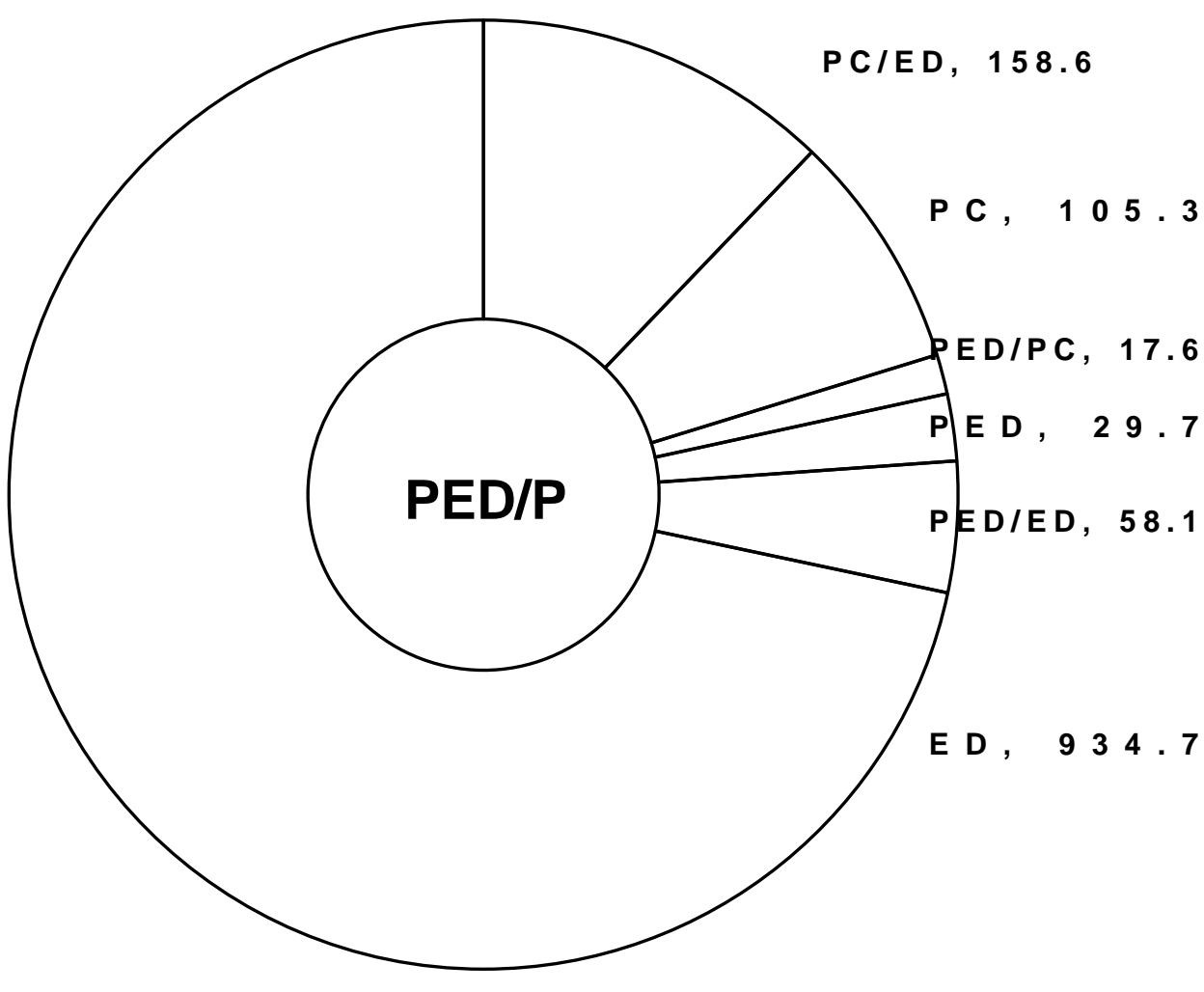

PED: $\quad$ Effect of parents' educations that is neither via parents' classes nor via children's qualifications.

PC: $\quad$ Effect of parents' classes that is neither via children's qualifications nor an indirect effect of parents' educations.

ED: $\quad$ Effect of children's qualifications that is neither an indirect effect of parents' educations nor an indirect effect of parents' classes.

PED/PC: $\quad$ Effect of parents' educations that is via parents' classes but not via children's qualifications.

PED/ED: $\quad$ Effect of parents' educations that is not via parents' classes but is via children's qualifications.

PC/ED: $\quad$ Effect of parents' classes that is via children's qualifications but is not an indirect effect of parents' educations.

PED/PC/ED: Effect of parents' educations that is both via parents' classes and also via children's qualifications.

Total effect of parents' educations

$=\mathrm{PED}+\mathrm{PED} / \mathrm{PC}+\mathrm{PED} / \mathrm{ED}+\mathrm{PED} / \mathrm{PC} / \mathrm{ED}=306.1$

Total effect of parents' classes

$=\mathrm{PC}+\mathrm{PED} / \mathrm{PC}+\mathrm{PC} / \mathrm{ED}+\mathrm{PED} / \mathrm{PC} / \mathrm{ED}=482.2$

Total effect of parents' educations and classes $=$ PED + PC + PED/PC + PED/ED + PC/ED

$$
+\mathrm{PED} / \mathrm{PC} / \mathrm{ED}=570.0
$$

Total effect of children's qualifications

$$
=\mathrm{ED}+\mathrm{PED} / \mathrm{ED}+\mathrm{PC} / \mathrm{ED}+\mathrm{PED} / \mathrm{PC} / \mathrm{ED}=1352.1
$$

Note: The size of each area within the above circle is proportional to the relevant model fit component. 
[Blank page] 